\title{
Escuela y procesos de construcción identitaria en la niñez indígena desde los dibujos en diálogo
}

\author{
Kathia Núñez Patiño ${ }^{1}$ \\ ORCID: 0000- 0002-0321-9572
}

\section{Resumen}

En este artículo se presenta el resultado del análisis de cuatro dibujos producidos y descritos por niñas y niños, de dos comunidades indígenas del estado de Chiapas, México. Estos dibujos son considerados textos semióticos y forman un corpus de documentos que permiten hacer una lectura y encontrar ciertas pistas, acerca de cómo interpretan su mundo en un campo semántico que da sentido a su entorno cotidiano, la escuela, en contextos complejos que estructuran su relación con las comunidades indígenas. Con una metodología y una gramática semiológica y etnográfica, los dibujos y sus propias descripciones permiten dar cuenta de imágenes e ideas de sí mismos como niños y niñas que, de formas diversas, son parte de una comunidad. En este análisis se articulan sus discursos y prácticas con sus procesos de identificación, para entender cómo es que ocurren estos procesos de configuración y creación identitaria en su vida cotidiana, desde los dibujos y las etnografías de sus contextos. En síntesis, se trata de mirar en uno de sus cimientos, la relación entre la cultura comunitaria y la cultura escolar, en distintas formas de asimilación, cambio y resistencia, bajo la experiencia de la autonomía indígena zapatista. Desde este abordaje, los dibujos configuran la recreación de herramientas de investigación que aspiran a la horizontalidad: en realidad, más que acompañados de una breve descripción a modo de entrevista, abren un diálogo con las niñas, los niños y sus contextos, en constante cambio.

\section{Palabras clave}

Identidad étnica - Niñez indígena - Metodologías horizontales.

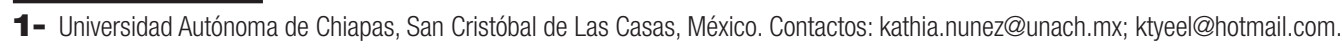




\section{School and identity construction in indigenous childhood from drawings in dialogue}

\section{Abstract}

This article presents the results of the analysis of four drawings produced and described by girls and boys from two indigenous communities in the state of Chiapas, Mexico. These drawings are considered semiotic texts and form a corpus of documents that allow reading and finding certain clues about how those children interpret their world in a semantic field that gives meaning to their everyday environment, the school, in complex contexts that structure their relationship with indigenous communities. With a semiological and ethnographic methodology and grammar, the drawings and the children's own descriptions allow us to account for images and ideas of themselves, like boys and girls who, in different ways, are part of a community. In this analysis, their discourses and practices are articulated with their identification processes, to understand how these processes of identity creation and configuration occur in their daily lives, from the drawings and ethnographies of their contexts. In summary, it is about looking at one of its foundations, the relationship between community culture and school culture, in different forms of assimilation, change and resistance, under the experience of the Zapatista indigenous autonomy. Based on this approach, the drawings configure the recreation of research tools that aspire to horizontality, so actually these drawings, more than accompanied by a brief description by way of an interview, open a permanent dialogue with girls, boys and their context in constant change.

\section{Keywords}

Ethnic identity - Indigenous children - Horizontal methodologies.

\section{Introducción}

El uso de dibujos para estudiar los procesos de construcción de la identidad con niños y niñas en comunidades indígenas, desde los aportes de la semiología y sustentada en la etnografía, representa una posibilidad de explicitar, por un lado, el contexto específico en el que se producen estos dispositivos considerando el espacio, el tiempo, el sentido de la actividad y los materiales que se usan y, por otro lado, los contextos sociohistóricos de los niños y niñas que los producen e interpretan, así como el de la investigadora que interviene en el proceso de producción y en su lectura, en la investigación. En resumen, se explicitan intereses y lugar de los y las actoras que participan en la producción de conocimiento, considerando la estructura de relaciones.

Los dibujos son abordados como un corpus de texto y la comprensión de su significación es el producto de dos series de operaciones: la producción y observación (de esta operación, se desprenden los procesos de lectura e interpretación). El texto 
es, de acuerdo con Ezquerro (2008a), un sistema que funciona en relación con otros dos sistemas complejos, que la autora denomina sujeto $A$ y sujeto $U$ y refieren a estos procesos de producción y observación, respectivamente, los cuales a su vez se encuentran interconectados con otros sistemas complejos que representan los contextos sociohistóricos y cognitivos de quienes participan en la investigación. Lo que Bajtín (1998) llamaría la unidad interior del sentido, porque "[...] un todo es mecánico si sus elementos están unidos solamente en el espacio y en el tiempo mediante una relación externa y no están impregnados de la unidad interior del sentido" (p. 11). Es decir, las posibilidades que los actores les otorgan a las estructuras de significación.

Los dibujos abren espacios para mirar los marcos de sentido generados por los actores en sus procesos de construcción identitaria, proveen de elementos vitales hacia una investigación dialógica, desde las dinámicas sociales e históricas de sus contextos, y permiten alejarse de un análisis esencialista de las comunidades indigenas que "[...] ha privilegiado la búsqueda de supervivencias de la antigüedad, considerándolas valiosas y 'puras' frente a elementos ajenos, propios de otras culturas, y que por lo tanto son “contaminaciones' para ellas” (ALEJOS, 2012, p. 11).

Con este principio de dinamismo y diversidad sociocultural de los contextos comunitarios, y considerando los marcos de sentido que construyen los niños y niñas manifestados en la producción de sus dibujos y las propias interpretaciones, se devela la idea hegemónica de la infancia y da cuenta de la diversidad de formas en las que vive la niñez.

La propuesta de análisis que se presenta aquí se desarrolla con la presentación de los actores que participan en la investigación y expone las posibilidades que abre el análisis de los dibujos desde una perspectiva antropológica y semiótica, para establecer relaciones dialógicas en la investigación. Con esta base, se expone la estructura de análisis de los dibujos en diálogo y sus contextos etnográficos, los cuales ofrecen las bases materiales y simbólicas que sustentan los procesos de construcción identitaria.

\section{Los actores de la investigación}

Este corpus está conformado por cuatro dibujos producidos por cuatro niños y niñas que viven en dos comunidades indígenas de Chiapas. Clara, de doce años y Antonio, de once años viven en la comunidad del municipio de San Cristóbal de Las Casas ${ }^{2}$, con orígenes del pueblo tsotsil de Huixtán, Chiapas. Sólo los padres mantienen su lengua originaria, y el padre reconoce la pérdida al no transmitirles la lengua a sus hijos, pero desde que forman parte de la base de apoyo civil de los zapatistas tratan de recuperar su lengua en la escuela autónoma. Su familia es extensa, además de sus once hermanas y hermanos, vive con ellos su pequeño sobrino de tres años.

La relación con esta familia lleva más de doce años y se ha construido a partir del activismo político en diversos espacios. Esta forma de situarse en la investigación privilegia

\footnotetext{
2- Por cuestiones solicitadas por los padres de los niños y niñas, no se da el nombre verdadero, son nombres que ellos eligieron para la investigación. En el caso del nombre de la comunidad ubicada en el municipio de San Cristóbal, tampoco pongo su nombre y se hace referencia a ella, como "la comunidad de San Cristóbal de Las Casas (SCLC)". En lo que refiere a la comunidad de El Bascán, nos permitieron dar el nombre de la comunidad, pero no el nombre verdadero de los niños y las niñas.
} 
un ojo desde dentro, pero también condicionado por las relaciones que implican un posicionamiento político explícito frente a los sujetos con los que hacemos investigación.

Paco y Nena, de seis años viven en la comunidad de El Bascán, municipio de Salto de Agua, Chiapas. La mayoría de los habitantes hablan ch'ol. Forman una familia extensa, con los abuelos y dos parejas jóvenes. Una pareja la forman los padres de Paco. Su madre es mestiza, una de las condiciones étnicas importantes para el análisis porque condiciona de manera ética la socialización de los niños, al ponerse en juego sentidos valorativos diferentes. Nena es prima de Paco y vive enfrente de su casa. En El Bascán no hay bases de apoyo zapatistas, al inicio del movimiento había alrededor de diez personas, pero en la clandestinidad. ${ }^{3}$

Con esta propuesta de análisis también se destaca la pluralidad de formas histórico y socioculturales de las infancias, se demuestra que es una categoría social permanente, pero no homogénea. La infancia se configura por el grupo social de niños y niñas que se desenvuelven en un espacio histórico y sociocultural específico.

\section{Los dibujos en diálogo considerados como textos semióticos: caminos para la horizontalidad en la investigación}

El tema de la escuela ha servido de guía para la producción de estos cuatro dibujos, que se conciben como un campo semántico y contituyen el texto (CROS, 1997). Es un espacio de significado, caminos de sentido o prácticas sociales. Son precisamente esas prácticas sociales las que busca la etnografía y gracias al trabajo de campo se concreta un contexto histórico, propio y vivo que da sentido último a la lectura de los datos, es decir, la historia local que es un parámetro indispensable para interpretar los signos del discurso, en los dibujos de los escolares.

El campo semántico de construcción de sentido se constituye en procesos sociohistóricos complejos, dinámicos y desde múltiples voces, constructores de identidad, es decir, los campos histórico-culturales a los cuales hace referencia el texto de la comunidad 4 . Un campo que produce los idiotopos, los cuales se constituyen de todos los elementos que en él participan:

[...] desde las características de la persona que escribe, su cultura, su biografía, hasta el conjunto de los posibles participantes secundarios en este proceso (maestros, discípulos, parientes, amigos,

3- La relación de investigación con esta comunidad se construye durante los estudios de maestría; así como ser parte de su entorno familiar, por tener una relación de matrimonio con mi compañero ch'ol. Desde entonces, he tenido enriquecedoras experiencias de aprendizaje continuo de los saberes y prácticas indígenas comunitarias, de lo cual estoy profundamente agradecida. En la primera experiencia de investigación se retribuyó con la organización del archivo ejidal y devolví la historia de la comunidad, la cual ha servido a los jóvenes cuando realizan solicitudes de beca académicas y les preguntan sobre la historia de su comunidad. En esta investigación, se estableció el acuerdo de contribuir con la instalación de una biblioteca comunitaria y el compromiso de mantenerla en colaboración, más allá de los tiempos de la investigación.

4- Este campo semántico forma parte de la investigación de tesis doctoral, la cual abarca 21 dibujos de tres campos: la comunidad, la casa y la escuela. Estos tres campos sirvieron de guía para la producción de los dibujos, en este ejercicio de análisis que se presenta sólo está centrado y profundizado en la escuela. En este artículo se presentan fragmentos de material de investigación recopilado en las comunidades de El Bascán, municipio de Salto de Agua, de origen ch'ol y una comunidad de origen tsotsil, ubicada en el municipio de San Cristóbal de Las Casas, las dos en el estado de Chiapas, México, durante el periodo de 2015-2017. Este material representa una parte sustantiva de etnografías más extensas, las cuales integran las voces de las niñas y los niños que se recopilaron con otras herramientas como fotografías, diarios y cartas (NúÑ̃EZ, 2018). 
prologuistas, editores, ilustradores, etc.). Esto como mínimo, sí se considera al sujeto "A" en sincronía con el proceso de producción. (EZQUERRO, 2008b, p. 9).

Los idiotopos emergen de los contextos culturales, desde los cuales los niños y niñas dibujan y leen sus producciones.

En este proceso de producción y lectura, el investigador también participa con sus propios idiotopos dentro de los dos subsistemas del texto. En la producción, al solicitar y acompañarlos en la elaboración de los dibujos, en una investigación con intereses concretos, explícitos, negociados y acordados con los niños, las niñas y las familias que participaron en ella. En la obervación-interpretación, desde sitios teóricos-epistemológicos y políticos que brindan un contexto específico en el que se leen los dibujos.

Estos dos marcos de sentido son construidos sobre la base de los contextos sociohistóricos de los subsistemas del texto, el sujeto que produce y el que hace la lectura, enfatizando que tanto las niñas y los niños como la investigadora participan en los dos. Los subsistemas están construidos en los contextos específicos donde se producen y leen los textos. Esta base sociohistórica y etnográfica produce lo que Ezquerro denomina semiotopo:

[...] el lugar nodal de la circulación del sentido, el lugar de encuentro de los dos sujetos del texto. El sujeto A, en tanto que productor del texto, da forma al semiotopo; el sujeto Ú, en tanto que observador, descodifica e interpreta los diversos elementos del semiotopo. Ambos desempeñan una actividad creadora en el sistema de comunicación textual. (2008a, p. 10).

Los distintos elementos de los dibujos son definidos como texto y considerados como dispositivos productores de diálogo, porque expresan imágenes y enunciados que generan un texto construido en un contexto, el cual "[...] es una construcción teórica abstracta que subyace a lo que normalmente se llama un discurso" (VAN DIJK, 1980, p. 32). En este ejercicio de análisis y con la finalidad de que este acto comunicativo trascienda en acto dialógico, se exponen las condiciones concretas de los procesos de producción y lectura; así como los contextos culturales que dan significado al sentido que le dan los actores, a estas ideas que van sustentando el análisis del proceso de construcción y recreación de la identidad de los niños, las niñas y la propia investigadora que producen, de nueva cuenta, un texto más.

Con esta propuesta metodológica para el análisis de los procesos identitarios con niñas y niños indigenas se explicitan los intereses y se privilegian las voces de los actores en la investigación, así como se visibiliza la manera en que se sitúan en sus contextos socioculturales. Al explicitar los intereses se abre el espacio para negociar y tomar acuerdos en los beneficios de la investigación y por lo tanto se originan oportunidades para la colaboración ${ }^{5}$. Si bien la colaboración es fundamental para la práctica de la etnografía, “[...] la realización de una etnografía colaborativa más deliberada y explícita

\footnotetext{
5- De estas relaciones que se han construido en la investigación al explicitar intereses y negociar beneficios en la producción de conocimientos se ha dado continuidad al trabajo de investigación, pero ya con un proceso consolidado de colaboración en la instalación de una biblioteca comunitaria en la comunidad de El Bascán, la cual fue producto de la reciprocidad para hacer la investigación de doctorado. Se inició con recursos propios de la autora, ahora se continúa con recursos del proyecto de investigación vigente "Bibliotecas comunitarias: diálogos interculturales y protagonimo infantil” (PRODEP - Programa para el Desempeño Profesional Docente 2019-2020).
} 
implica resituar la práctica colaborativa en todas las etapas del proceso etnográfico, desde el trabajo de campo hasta la escritura y viceversa" ${ }^{6}$ (DENZIN, 2005, p. 15). Alcanzar este nivel de colaboración es difícil dentro de las estructuras hegemónicas de producción académica que dependen de los recursos y el marco normativo para su realización.

Desde esta definición general de la colaboración en la investigación se pueden distinguir niveles, desde el más básico que es considerar a los actores no como informantes, sino como colaboradores en tanto co-intelectuales, reconociendo su agentividad y como co-productores de significados (DENZIN, 2005). Lo anterior implica establecer la relación de igualdad en la investigación horizontal que propone Corona (2007) al reconocer la igualdad de inteligencias entre los participantes en relaciones que la autora denomina entreculturales.

Lo anterior no niega la relación de poder, sino que la explicita, porque frente a la estructura inflexible de las instituciones académicas el ideal de todo el proceso de la investigación considerando desde la elección del problema, la metodología, los métodos, la distribución y asignación de recursos, hasta la escritura o producto de la investigación, la hace casi imposible. Ante este aparato burocrático "[...] el intercambio horizontal y reciproco es el punto de partida para producir conocimientos, cuyas condiciones deben ser negociadas permanente con los otros en el campo" (CORONA; KALTMEIER, 2012, p. 12) $\mathrm{y}$ también dar continuidad a las relaciones y procesos de producción del conocimiento.

\section{Estructura de análisis interno del texto: los elementos del corpus en los dibujos de la escuela}

Los elementos que integran el corpus del texto, es decir los dibujos en diálogo, son los niños y las niñas, entre los seis y doce años, que viven en dos comunidades identificadas como indígenas del estado de Chiapas. Con los y las autoras está la investigadora, kaxlana, estudiante de doctorado que pide que se realicen los dibujos para la investigación, sustentada en el objetivo general de conocer los procesos de construcción y creación identitaria de esos niños y niñas en sus contextos comunitarios indígenas. Estos son los actores que conforman el subsistema del sujeto $A$, el productor.

El otro subsistema también lo integran estos niños y niñas que interpretan sus propios dibujos y la investigadora que les solicita describir sus dibujos a través de breves preguntas sobre lo que hacen ahí, lo que les gusta y lo que no de cada uno de los ámbitos de sentido que dibujaron. Cada uno hace la lectura, desde el entramado de sus propios contextos. Por un lado, desde contextos comunitarios indígenas dinámicos y atravesados por complejos procesos de despojo, asimilación y resistencia. Por el otro, el de la propia investigadora en su contexto cultural de la academia, el activismo político, la docencia-investigación universitaria y la vida doméstica en contextos interculturales, cruzado por el género y la clase.

Los elementos de la producción e interpretación para el análisis de la construcción de identidades genera el semiotopo, es decir, las funciones de los sujetos $A$ y $U$. La forma, los dibujos y la decodificación o interpretación de los elementos del texto: el encuentro entre los sujetos del texto para identificar las diversas ideas que surgen de la multiplicidad

6- Traducción propia. 
de voces en los distintos ámbitos de sentido o campos histórico culturales e interculturales; de las cuales, los niños y las niñas que participaron en la investigación van integrando, adaptando, creando o desechando de manera compleja, en base al lugar que ocupan en su espacio social y a sus posibilidades reflexivas para reproducir o transformar estas ideas.

Son estas voces que desde los aportes bajtinianos se denomina heteroglosia (BAJTÍN, 1998) y que coexisten en las distintas dimensiones constructoras de identidad en las estructuras de relaciones sociales. Éstas se pueden identificar en los dibujos y la propia observación-lectura-interpretación. Esta interpretación que hacen las niñas y los niños de sus propios dibujos genera lo que en los estudios semiológicos se denomina ecfrasis (ARTIGAS, 2014). Esta producción de los dibujos aporta también una descripción de los propios autores $\mathrm{y}$, en tanto descripción de los dibujos, es útil porque aporta elementos no presentes de manera explícita en el dibujo, es el propio autor interesado en destacarlos. Son ideas o enunciados que permiten establecer actos comunicativos, de tal forma que el enunciado, que se puede identificar dentro de estas producciones, "[...] debe entenderse como un fenómeno en esencia dialógico, un acto de habla y una relación social, una relación intersubjetiva, es decir, una interacción entre yo y otro, que atraviesa los planos cognitivos, ético y estético" (ALEJOS, 2012, p. 29). Este fenómeno dialógico se construye en una estructura de poder, a partir de la cual se construyen discursos que legitiman la estructura dominante.

\section{Los contextos sociohistóricos de los actores en la producción-lectura del texto a través de los dibujos en diálogo}

El proceso actual que atraviesan las comunidades indigenas, con la penetración cada vez más fuerte del capitalismo, genera un consumo y uso del dinero como forma más común para resolver la vida cotidiana. Esta penetración ha profundizado el despojo de sus recursos, así como el desplazamiento de sus prácticas comunitarias y saberes que les han permitido su continuidad en un mundo que se construye en la lógica de la dominación, la explotación y el despojo.

Estas prácticas y saberes comunitarios que al mismo tiempo han brindado la base para la resistencia de los pueblos, deviniendo alternativas para la transformación de las relaciones que promueven los proyectos políticos liberales y neoliberales del mundo occidental, donde el mercado es dominante. De ahí el interés por conocer la manera en que se producen los discursos y las prácticas comunitarias, la manera en cómo se van integrando o resistiendo las de orden liberal al servicio del orden capitalista en los dos contextos comunitarios, en su mayoría indígenas, con procesos históricos semejantes, pero también en procesos de cambio y continuidad diversos.

Los contextos comunitarios son muy diversos, por lo que los fundamentos del poder comunal, sustentado en la tierra comunal, como las asambleas, el trabajo comunal y las fiestas (PÉREZ RUÍZ, 2009) se tienen que comprender en estas prácticas comunitarias indígenas, en las que se van configurando las identidades de la niñez, con base a una red de pertenecias sociales, un sistema de atributos distintivos y la narrativa de una memoria colectiva; las cuales se presentan de manera específica en cada contexto particular y se 
articulan en la dinámica de transformación de los contextos de relación en los procesos de historicidad y movimientos, así como en el carácter político simbólico de las fronteras identitarias, su plasticidad, los referentes de distintividad y los recursos desde los cuales se delimitan (MEDINA MELGAREJO, 2007).

La comprensión de estos elementos permite atender la

[...] historicidad de procesos de identidad étnica y etnicidad, entendida como un espacio de relaciones de tensión producto de las diferencias histórico-culturales, que requiere de la comprensión de procesos desde contextos específicos en la trayectoria de un pueblo determinado. (MEDINA MELGAREJO, 2007, p. 179).

Esta comprensión nos puede acercar al complejo sistema valorativo que sustentan las relaciones de reciprocidad y solidaridad comunitaria en el que se hace comunidad y donde:

[...] la comunidad debe comprenderse como producto de una gran diversidad de factores económicos, políticos y culturales unos, y emocionales y simbólicos, otros- que conducen a sus miembros a solidarizarse, a tomar decisiones y a desarrollar acciones en las que se ponen en juego relaciones de poder, posiciones de clase y de estatus, las diferencias religiosas y políticas, así como los diversos proyectos para el presente y futuro de lo que debe ser la comunidad. (PÉREZ RUÍZ, 2009, p. 95).

De esta manera, se registraron las dinámicas en las que se presentan estos elementos en los dos contextos comunitarios indígenas, en un contexto de continuo despojo de prácticas, saberes y territorios, unos más fuertes que otros, dependiendo de los contextos específicos de dominación y resistencia en sus trayectorias históricas. En cada uno de estos contextos, vividos desde el campo semántico de la escuela que da cuenta de estas dinámicas a partir de las ideas que van configurando los idiotopos, es decir las diversas voces y las prácticas culturares, que en procesos complejos, van generando identidad, en tanto un proceso más consciente y explícito que retoma y revalora mediante procesos culturales rutinizados, creando y fortaleciendo nuevas prácticas culturales que pueden también ser rutinizadas (JIMÉNEZ NARANJO, 2009). Algunas de estas prácticas indígenas comunitarias se han convertido en parte medular de los proyectos políticos, emanados de los movimientos sociales, como el zapatista. Por ejemplo, el trabajo colectivo o el mandar obedeciendo ${ }^{7}$ que se manifiesta en las asambleas comunitarias, la solidaridad y la reciprocidad.

Aqui la complejidad y profundidad de los procesos culturales que generan identidad en una gran diversidad de posibilidades de continuidad y cambio en las prácticas culturales comunitarias indigenas. Por tanto, la importancia de estas prácticas comunitarias, en algunos casos rutinizadas pero fuertes, unas más que otras en contextos específicos, pero que han permitido la continuidad de los pueblos y comunidades. Prácticas que, en el caso de los movimientos indígenas como el zapatismo, se han convertido en un aporte

7- Sintetiza las prácticas concretas de la forma de gobierno en las comunidades indígenas, donde el cargo político es un servicio comunitario y no una posición de poder, donde el que manda es el pueblo. Al tiempo que es una crítica a la clase política en México, desde el movimiento zapatista, que ha obtenido poder político y económico al imponer sus intereses y no las del pueblo. 
fundamental que, desde su práctica de autonomía cotidiana, genera proyecto político. El cual se explicita en sus escuelas y pilares de la autonomía: la salud, la justicia y los trabajos colectivos, aportando una base de análisis para la creación de posibilidades de resistencia al despojo de prácticas, que promueven la acción política frente al individualismo indiferente y dependiente de las estructuras sociales al servicio del mercado (COMISIÓN SEXTA, 2015).

En el siguiente apartado se presenta el contexto escolar desde su campo semántico de la escuela, destacando los elementos de tensión, conflicto y disputa por el sentido de la acción y la construcción identitaria. El contexto etnográfico ofrece el susteto material y simbólico, es el lugar nodal de la circulación del sentido y de encuentro entre los dos sujetos que producen y leen el texto.

\section{La escuela desde la etnografía y los dibujos en diálogo}

Las escuelas en las que se centró el relato etnográfico son la escuela autónoma de la comunidad de San Cristóbal y el preescolar de la comunidad de El Bascán. La elección del nivel preescolar es por considerarlo un espacio que desde los primeros acercamientos al campo llamó mi atención por la dureza con que se imponía a los niños pequeños la cultura escolar. En ese entonces hacía etnografía en la escuela primaria, por lo que ahora centré la atención en el pre-escolar y durante el trabajo de campo Paco y Nena cursaban el tercer grado de ese nivel escolar. Se muestra cómo este campo cultural gana espacio en la transmisión de las metas y valores que ahí se expresan, en la construcción de las identidades de los niños.

En el caso de la escuela autónoma, la información etnógrafica se sustenta en mayor medida con la propia información de los dibujos, complementada con la narración que hicieron sobre un día en su escuela autónoma. Lo anterior se debe a las condiciones restrictivas por ser bases de apoyo zapatista y porque por ahora no hay niños en edad escolar que acudan a la escuela. La información de la escuela autónoma se complementa con visitas realizadas en 2011 a la comunidad.

Antonio y Clara fueron parte de la última generación de la escuela autónoma, pero en comunidades de la región hay escuelas autónomas que funcionan con regularidad. Ya no continuaron su formación porque la secundaria autónoma está en Oventik y les queda muy lejos. Sólo una hija y dos hijos de Don Antonio continuaron con este nivel, en el que comienzan a formarse como promotores de las distintas áreas de las autonomías zapatistas: salud, educación, agroecología y medios ${ }^{8}$.

De esta manera, la escuela autónoma en la comunidad de San Cristóbal se construye cuando Don Antonio ingresa como base de apoyo zapatista, por el año 2000:

[...] la demanda que hizo el EZ es para que ellos iban a construir, como la educación, la salud, lo mismo pues, ya la educación pues nosotros tuvimos que construir mismo y los promotores pues solamente llevan capacitaciones y sí había mucho avance, cuando había varios niños,

8- Para profundizar en la estructura y funcionamiento de las escuelas autónomas zapatistas, consultar Baronnet, Mora y Stahler-Sholk (2011) en el apartado de Educación y resistencia. 
hasta 22 parece que llegaron los niños, cuando estaba trabajando el promotor, ahí sí avanzó mucho y era suficiente, pero cuando fue [...] bueno, la verdad, no es porque[...] fue terminando, nosotros más que nada, fue acabando los niños, era nada más Clara, Antonio, otro niño... nada más, con tres niños estuvo trabajando dos años el promotor, después ya no hubo nada, terminó. (Don Antonio, 28-11-2015).

Ahora Don Antonio espera que nazcan y crezcan niños para tener un nuevo grupo, aunque el espacio lo usan para tener reuniones porque el edificio suele ser un espacio multiusos. La escuela, como describe Clara, tiene una resbaladilla, niños que juegan, el maestro, los alumnos, los árboles, el sol, la escuela y flores. En la escuela hacen muchas otras cosas, así narra Clara un día en la escuela autónoma:

Por decir, sacábamos nuestros borregos, veníamos a almorzar antes, íbamos en la escuela, entrábamos a las 9 y hacíamos puros temas de, temas de [...] las tareas de agroecología, salud, humanismo, este, higiene personal y ya a la hora de receso, era a las 11, ya entrábamos a las 11:30 parece, ya a las dos de la tarde, ya salíamos, ya veníamos y estudiábamos pues, de agroecología, todos esos temas que veíamos. (Clara, 21-11-2015).

Dibujo 1- La escuela

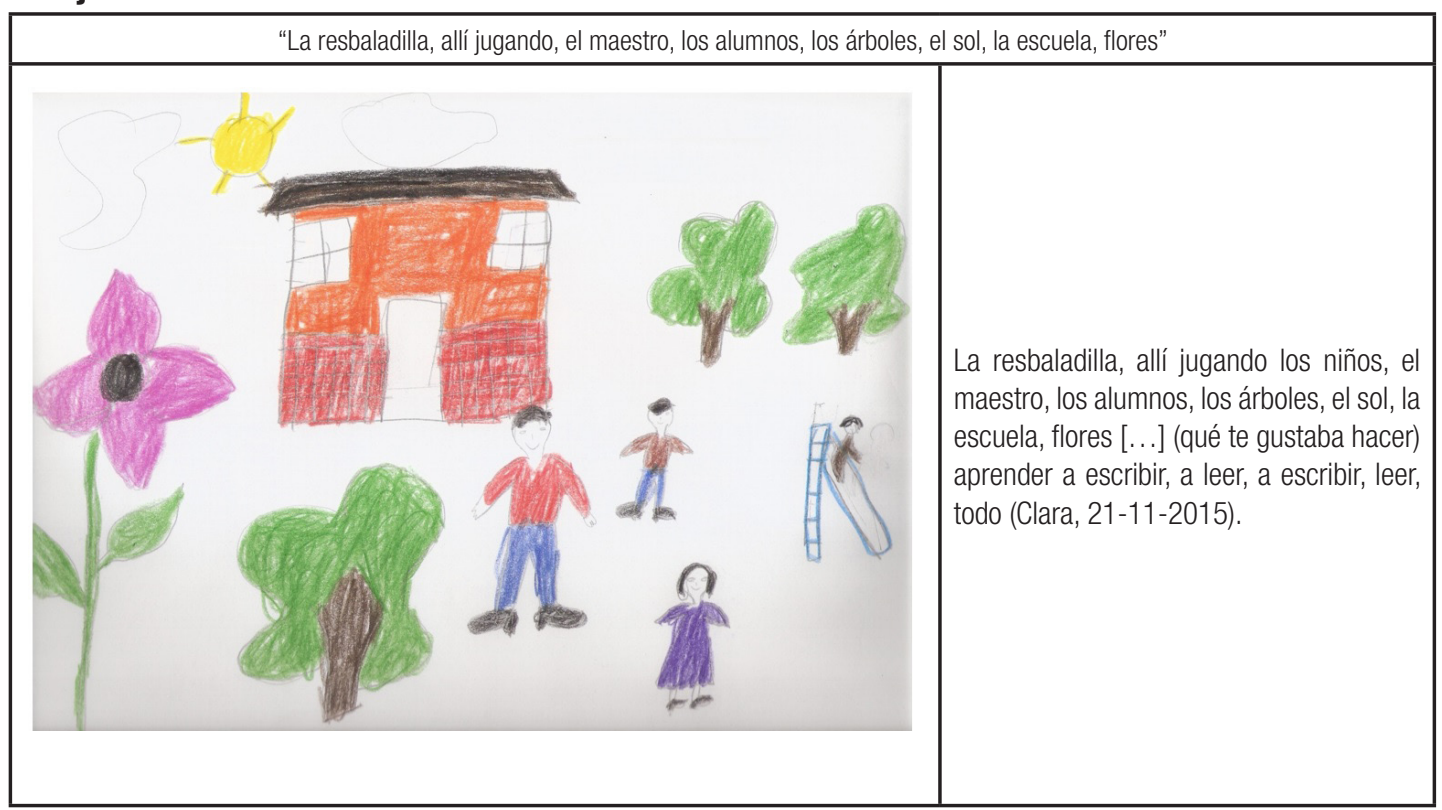

Fuente: Datos de la investigación.

La relación del promotor de una escuela autónoma es casi siempre de familia, en este caso es el tío de Clara y Antonio, pero se establece una relación de hermano mayor, por lo que de la casa se traen a la escuela las relaciones afectivas en el aprendizaje que se da entre los hermanos. Otro de los saberes eje de los niños es el trabajo de la tierra que lo 
refuerzan en el aula porque durante la entrevista Clara confirma que esos conocimientos ya los tenía, pero integran en la escuela autónoma nuevos. Clara nos narra lo que ya sabía hacer y hacen en la clase de agroecología:

Primero quebrar con mancuerna de toro, sembrar, después ya va criando pues ya la milpa, tapiscarlo ya es para nuestro alimento y eso es agroecología, sembrar verduras, frijol, tomate, así lo que crían en esta tierra pues, ahí lo sembramos, ahí en agroecología... donde no "supíamos" de abono y ya ahí empezamos a juntar estiércol de ganado, echar en las milpas para que crezca más la milpa (21-11-2015).

Lo que Clara no sabía era parte de toda una serie de saberes y prácticas que tenían sus abuelos porque Don Antonio ya había compartido conmigo y mis estudiantes en una ocasión, lo que les costó recuperar sus tierras de los agroquímicos que el Estado comenzó a imponer en la década de los setenta. Nos explicaba del impacto, no sólo en la deforestación de la tierra, sino también en sus prácticas del trabajo colectivo, porque el trabajo de limpiar la milpa con machete les llevaba como una semana, con los agroquímicos se reducía a un día, pero también se reducía una larga lista de alimentos que crecen a alrededor de ella, así lo exponía Don Antonio:

[...] quien no quiere trabajar menos, pero después, ya no se producía nada, pero con la organización, nos costó cuatro años recuperarla, fue difícil, pero lo hicimos con lo que había en la comunidad, lo que antes usaban nuestros abuelos y que con los agroquímicos tirábamos, lo convertimos en composta y cultivo de gusanos, que nos permite nutrir la tierra de la milpa y de nuestras hortalizas. (NÚÑEZ, 2013, p. 87).

De esta manera, la escuela autónoma zapatista se vuelve un espacio de recuperación y reflexión de las prácticas y saberes que han sido despojados y desvalorizados, a través de formas de despojo disfrazadas de políticas públicas, dirigidas a los pueblos y comunidades indígenas. Antonio por su parte, afirma que a él le gusta:

[...] aprender, saber escribir y saber hacer mis cuentas, así es por eso que me gustaba la escuela [...] lo que más hacíamos era escribir, escribíamos con mi tío [...] nos daba de dibujar, de escribir, salíamos a receso, salíamos a jugar, entrábamos, empezábamos a hacer [...] a veces nos daba [...] jugábamos con el maestro ahí, mi maestro así [...] ¡Ah, sí! Hacíamos ejercicio también, de todo [...] si era diferente, sí porque los demás no cuidaban mucho su salón [...] nos decía a nosotros que teníamos que aprender más, porque ellos, la verdad, no escriben bien ellos [...] nosotros también no escribimos bien, pero ahí íbamos así. (Antonio, 28-11-2016).

Lo que narra Antonio deja ver entrelíneas este otro conocimiento que les genera bases de reflexión sobre su responsabilidad y conciencia como zapatistas, cuando señala que "los demás" no cuidan su salón y al señalar que "nosotros teníamos que aprender más". 
Dibujo 2- La escuela

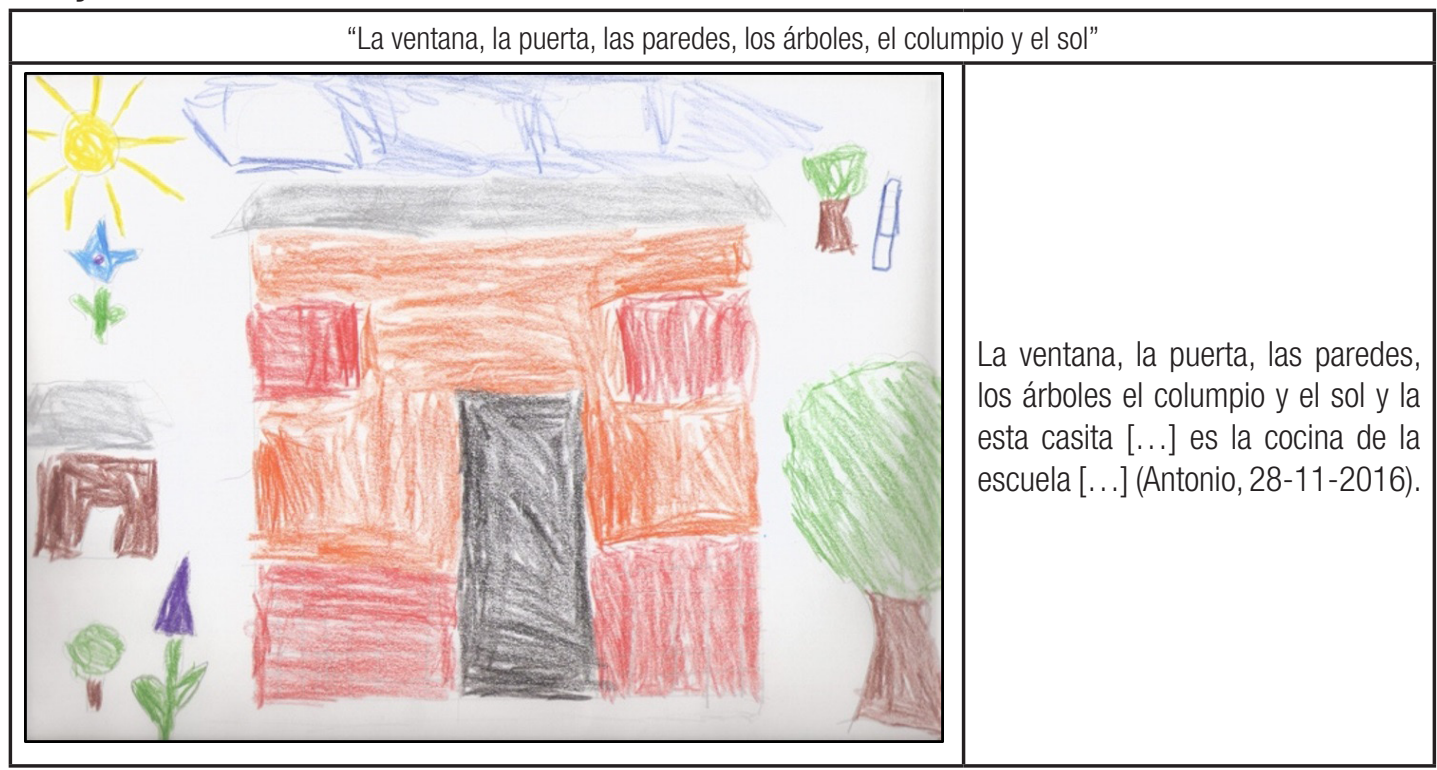

Fuente: Datos de la investigación.

En la escuela del municipio Salto de Agua, al prevalecer la obligatoriedad del nivel preescolar, se profundizan los cambios en la socialización infantil en el contexto cultural de la familia y la comunidad, el cual se ve drásticamente reducido, otorgando mayor espacio a la escuela que desprecia las lenguas y culturas originarias. Por ejemplo, los niños del nivel preescolar ya no toman los alimentos en casa durante el receso. Ahora lo hacen dentro de la escuela llevando de manera individual su lunch (almuerzo).

Estos procesos de cambio son los que han llevado a centrar la atención en este nivel escolar porque durante el trabajo de campo de los estudios de maestría mientras hacía etnografía del aula, llamó mi atención que los niños pequeños tomaban sus alimentos sentados en el piso, afuera del salón, cosa que no hacían en la primaria. Al terminar de tomar alimentos, observé una actividad dirigida por la maestra como parte de su receso. La actividad me impactó porque la maestra les ordenaba a los niños hacer una rueda y caminar al tiempo que ella les marcaba el paso con una vara de madera. Esta actividad contrasta con las actividades cotidianas del contexto cultural comunitario, el cual les ofrece a estos niños desde su primera infancia, una amplia libertad que choca culturalmente con las estrictas rutinas impuestas por el sistema escolarizado, ahora desde los tres años de edad en el nivel preescolar.

Esta reducción de los espacios de socialización comunitarios se complejiza más con el dinamismo que envuelve a las comunidades indígenas y sus relaciones más intensificadas con los centros urbanos y la migración, los cuales se amplían por las 
necesidades que abre la escuela en búsqueda de continuar las trayectorias escolares o de empleos que ya nada tienen que ver con el trabajo agrícola. Durante la etnografía del aula, el trabajo de campo reciente, se registró lo complejo de los espacios áulicos que se ven condicionados por determinados contextos políticos y magisteriales que provocan experiencias distintas de un aula a otra.

Esta diversificación del aula escolar, desde una nueva historiografía que destaca Bertely (2008), obliga a mirar la escuela desde dentro y entenderla como un entramado cultural que se construye desde el interior, muchas veces desde los márgenes institucionales. Con este planteamiento se abren posibilidades para estudios más profundos de los procesos educativos y la participación de los actores en él. Para este trabajo, Bertely (2008) aporta dimensiones centrales para entender la diversidad de relaciones que se construyen entre la escuela y la comunidad.

[...] un concepto de cultura escolar, alternativo que mira la escuela desde fuera y coloca su atención en (i) los diferentes usos atribuidos al proceso de escolarización en las distintas sociedades y grupos culturales, así como en (ii) la acción social, la acción cultural y la acción política como las tres dimensiones en que intervienen en lo que es y puede llegar a ser la escuela en las sociedades tribales e indígenas" (p. 34).

En el salón de clase de tercero de preescolar de la comunidad de Salto de Agua, la maestra está adscrita al Sindicato Nacional de Trabajadores de la Educación (SNTE), llamado también sindicato charro por su línea progubernamental y ha tenido dificultades con la comunidad, pues muchos habitantes muestran simpatías por la corriente disidente. La profesora que atiende la dirección y el aula multigrado de primero y segundo está adscrita a la Coordinadora Nacional de Trabajadores de la Educación (CNTE). Por ende, las tensiones entre docentes son notorias.

Frente a estos cambios producidos por las reformas educativas que establecieron la obligatoriedad del nivel preescolar, las niñas y los niños pasan las cuatro horas que establece la formación preescolar, sin salir a sus casas a tomar los alimentos. Pero de acuerdo a las condiciones concretas de cada maestro, cambian de aula en aula. Durante el receso, se observan diferencias en las prácticas escolares en torno a los desplazamientos de los alumnos. En el grupo de tercer grado, la circulación infantil parece más libre. Salen y entran del salón a menudo. Algunos corren, otros bailan, pues la maestra trabaja con una grabadora donde pone música infantil, la cual es manipulada por los propios niños. Esto no es realmente común en las aulas del sistema escolar oficial en las que se han registrado experiencias etnográficas previas (NÚÑEZ, 2005; BARONNET, 2012). 
Dibujo 3- La escuela

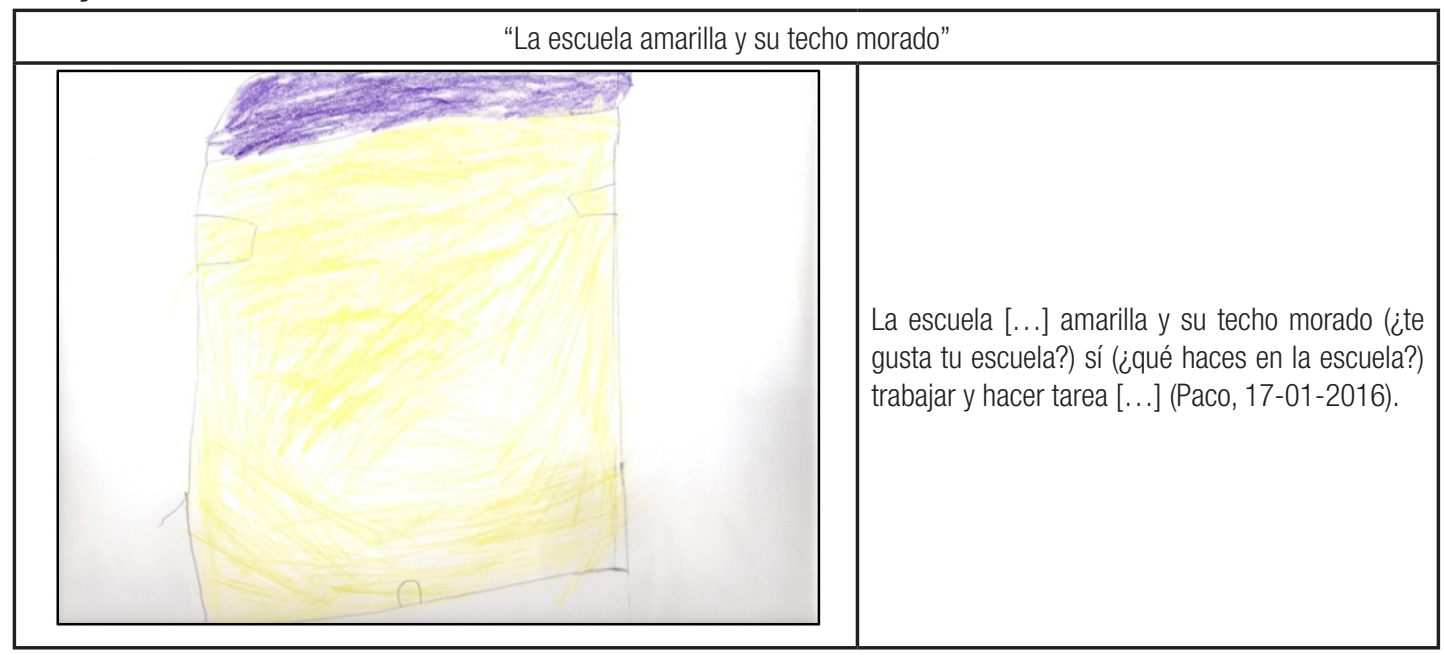

Fuente: Datos de la Investigación.

Los niños del aula multigrado de primero y segundo grados están calmados, sentados en las sillas del salón, alrededor de la maestra, comiendo alimentos. Está situación contrasta con la actividad más dinámica de los niños en sus casas. Es sorprendente constatar cómo el salón de clase se encuentra cerrado con cadena que la maestra abre y cierra. La madre de un niño confirma el hecho que es permitido por los padres de familia, comenta que ahora es peligroso para los niños caminar o correr por las calles porque los carros de transporte entran con velocidad. Es aceptado entonces que la docente cierre la puerta porque los más pequeños tratan de escapar de la escuela y al salir corriendo se exponen a ser atropellados.

Cabe mencionar que en esta comunidad es bastante reciente la intensificación de la circulación de vehículos de transporte público. Ello impacta en la socialización dentro de la comunidad, cuando hace algunos años se podía observar un espacio de gran seguridad, donde los niños y las niñas se podían mover con mayor libertad. Ahora se encuentran altamente restringidos por la obligatoriedad escolar, la entrada más continua de vehículos y los cambios en los estilos de crianza derivados también de matrimonios interculturales entre parejas de distintos orígenes.

Estas transformaciones socioculturales, así como las políticas neoliberales en materia educativa, están minando prácticas colectivas de cooperación interpersonal. La construcción de identidades en la infancia se moldea también a través de la individualización de la alimentación infantil que favorecen los programas asistencialistas del Estado a través de la escuela.

De esta manera el conflicto entre escuela y comunidad es permanente y lo que he podido registrar por más de doce años en visitas realizadas de manera continua es que cada vez más la niñez de la comunidad desconoce las plantas, árboles y animales locales, pero los árboles de manzanas, que no son parte de su contexto local, están muy presentes 
en sus actividades cotidianas escolares. En la ecfrasis de Nena nos cuenta que le gusta escribir y hacer manzanas en su escuela.

Dibujo 4- La escuela

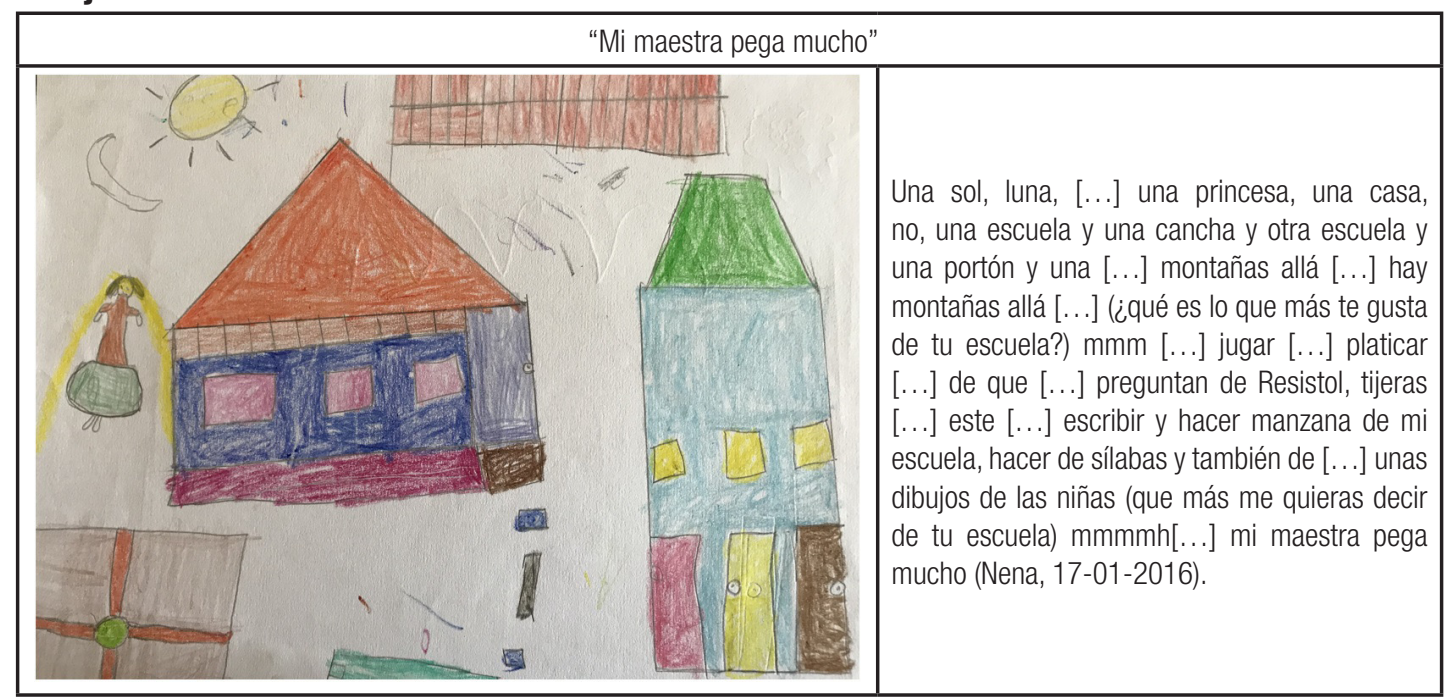

Fuente: Datos de la investigación.

En particular llaman mi atención las prácticas escolarizadas en las que se contradicen las reglas estrictas en la disciplina, donde cada quien debe hacer su tarea entre lo estricto y la simulación porque no se permite una serie de cosas que restringe las capacidades de movimiento e interacción entre los niños. Como señalaba Nena que a ella le gusta en la escuela platicar para prestarse resistol o tijeras porque a pesar de que está restringido este tipo de interacciones, los niños casi siempre encuentran formas para transgredirlo. No obstante, las consecuencias recibidas como el maltrato que la propia Nena denuncia: "mi maestra pega mucho".

Esta preponderancia del contexto escolar sobre el contexto comunitario, que había dezplazado las prácticas culturales en El Bascán, fue evidente en la última visita, ya que al estar en pleno proceso el paro magisterial de la CNTE en contra de las Reformas Educativas, las niñas y los niños no habían tenidos clases. Este cierre de la escuela permitió una reapropiación del territorio y mayor participación en las prácticas culturales, que la escuela había desplazado. Estaba con ellas y ellos en la casa del abuelo, después de haber ido a la asamblea ejidal les propuse ir al arroyo, me dijeron que sí y me sorprendí mucho porque fue la primera vez que las madres les permitieron ir sin su supervisión. Pero mayor fue mi sorpresa cuando en el arroyo de la comunidad me platicaban todas las actividades que hacían al no haber clases: aprendieron a nadar, conocieron el arroyo más arriba y hablaban de muchas frutas y plantas que conocieron en sus recorridos, fueron a pescar al río Bascán, un río muy caudaloso que está cerca de la comunidad y da su nombre (Registro diario de campo, 29-08-2016). Estas actividades eran sus prácticas cotidianas desde edades muy tempranas (NÚÑEZ, 2005). 
Lo anterior describe con mayor claridad esta falta de articulación que posibilita a los niños dar continuidad a los procesos de aprendizaje entre los conocimientos de la escuela y la comunidad. En lugar de esta articulación, continúa la función de la escuela en el modelo del Estado nación en tanto proceso de la colonialidad del poder (QUIJANO, 2000), en la que despojan a los pueblos de sus saberes y recursos, a cambio de una integración donde los derechos sociales son restringidos y de la más baja calidad.

\section{Los dibujos en diálogo desde un análisis etnográfico y semiológico de textos}

Hasta ahora se describió y se dio cuenta de cuatro aspectos del texto: las condiciones de producción, los elementos del texto: la comunidad (un dibujo y su ecfrasis-exégesis por cada niño y niña), las etnografías de los contextos comunitarios y una primera lectura del texto. En el Cuadro 1 se sistematizan los elementos de esta primera lectura del contenido de los dibujos en un proceso de deconstrucción, o sea, una reordenación de los signos que van organizando un discurso.

Cuadro 1- Descripción de los elementos del dibujo y su exégesis del tema: La escuela

\begin{tabular}{|c|c|c|c|}
\hline Autor & Elementos & Ecfrasis & Exégesis \\
\hline $\begin{array}{l}\text { Dibujo 1. La escuela } \\
\text { Clara, } 12 \text { años } \\
\text { Comunidad de SC } \\
\text { Fecha: } 28 \text { de noviembre de } \\
2015\end{array}$ & $\begin{array}{l}\text { Edificio } \\
\text { Árboles } \\
\text { Resbaladilla } \\
\text { Sol } \\
\text { Nubes } \\
\text { Flor } \\
\text { Personas }\end{array}$ & $\begin{array}{l}\text { La resbaladilla, allí jugando los niños, el } \\
\text { maestro, los alumnos, los árboles, el sol, la } \\
\text { escuela, flores [...] (qué te gustaba hacer) } \\
\text { aprender a escribir, a leer, a escribir, leer, } \\
\text { todo. }\end{array}$ & $\begin{array}{l}\text { Nombra todos los elementos del dibujo } \\
\text { y expresa que los niños están jugando. } \\
\text { Agrega lo que hacen en la escuela: leer, } \\
\text { escribir, aprender. }\end{array}$ \\
\hline $\begin{array}{l}\text { Dibujo 2. La escuela } \\
\text { Antonio, } 11 \text { años } \\
\text { Comunidad de SC } \\
\text { Fecha: } 28 \text { de noviembre de } \\
2015\end{array}$ & $\begin{array}{l}\text { Edificio } \\
\text { Árboles } \\
\text { Resbaladilla } \\
\text { Sol } \\
\text { Flores }\end{array}$ & $\begin{array}{l}\text { La ventana, la puerta, las paredes, los } \\
\text { árboles el columpio y el sol y la esta casita } \\
{[\ldots \text {... es la cocina de la escuela. }}\end{array}$ & $\begin{array}{l}\text { Describe lo que dibuja, sin agregar más } \\
\text { elementos: la ventana, la puerta, las } \\
\text { paredes, los árboles el columpio y el sol } \\
\text { y la casita que es la cocina de la escuela. }\end{array}$ \\
\hline $\begin{array}{l}\text { Dibujo 3. La escuela } \\
\text { Paco, seis años } \\
\text { Comunidad El Bascán } \\
\text { Fecha: } 17 \text { de enero de } 2016\end{array}$ & Edificio & $\begin{array}{l}\text { La escuela [...] amarilla y su techo morado } \\
\text { (¿te gusta tu escuela?) sí (¿qué haces en la } \\
\text { escuela?) trabajar y hacer tarea. }\end{array}$ & $\begin{array}{l}\text { Sólo lo describe, señala lo que le gusta, } \\
\text { que ahí trabaja y hace tarea. La escuela } \\
\text { como um ente aisaldo. }\end{array}$ \\
\hline $\begin{array}{l}\text { Dibujo 4. La escuela } \\
\text { Nena, seis años } \\
\text { Comunidad El Bascán } \\
\text { Fecha: } 14 \text { de septiembre de } \\
2016\end{array}$ & $\begin{array}{l}\text { Sol } \\
\text { Persona } \\
\text { Cancha } \\
\text { Formas } \\
\text { Edificios }\end{array}$ & $\begin{array}{l}\text { Una sol, luna, }[\ldots] \text { una princesa, una casa, } \\
\text { no, una escuela y una cancha y otra escuela } \\
\text { y una portón y una }[\ldots] \text { montañas allá }[\ldots] \\
\text { hay montañas allá }[\ldots] \text { (¿qué es lo que más } \\
\text { te gusta de tu escuela?) mmm [...] jugar } \\
{[\ldots] \text { platicar }[\ldots] \text { de que }[\ldots] \text { preguntan }} \\
\text { de Resistol, tijeras }[\ldots] \text { este }[\ldots] \text { escribir } \\
\text { y hacer manzana de mi escuela, hacer de } \\
\text { sílabas y también de }[\ldots] \text { unas dibujos de } \\
\text { las niñas (que más me quieras decir de tu } \\
\text { escuela) mmmmh[...] mi maestra pega } \\
\text { mucho. }\end{array}$ & $\begin{array}{l}\text { Describe su dibujo. Sólo dibuja una } \\
\text { montaña, pero señala que hay montañas } \\
\text { allá. Le gusta, escribir, hacer manzanas } \\
\text { y dibujos de las niñas, también jugar y } \\
\text { platicar para pedir resistol o tijeras, a } \\
\text { pesar de que no es permitido. Denuncia } \\
\text { que: "mi maestra pega mucho". }\end{array}$ \\
\hline
\end{tabular}

Fuente: Elaboración propia. 
Un discurso que se va construyendo del estudio de las cualidades visuales: ¿qué vemos? (colores, líneas, volúmenes); segmentación de la superficie en grandes áreas y regiones; notar en cada segmento o región las unidades significantes o elementos y ubicarlos en relación con otros signos. Se enlistan los elementos y correlacionan los signos a partir de semejanza y de opuestos para encontrar los campos semánticos y campos semióticos que se integran en los relatos etnográficos.

Finalmente se sintetiza el texto: son dibujos de niños en edad escolar. Hechos con lápices de colores. Los trazos son sencillos y remiten a sus casas. Formas cuadradas para representar las habitaciones, árboles y soles al estilo de la enseñanza escolar mexicana. Se identifica un rasgo icónico en todos los objetos: cada objeto dibujado remite a un ente concreto, por una relación de semejanza. Todos los elementos tienen esta característica. El sol, por ejemplo, dibujado como un círculo rodeado de rayos, normalmente de color amarillo, o los edificios, dibujados con un cuadrado y un triángulo o trapecio, a manera de techo. Se puede decir que son figuras estandarizadas, signos típicos para remitir a los objetos sol y casa que los niños suelen aprender en el aula, desde el preescolar, influencia de la educación formal que se ha señalado y sobre la manera como los mexicanos concebimos el entorno. Esta forma del lenguaje que se expresa en los dibujos dirigió la lectura del texto, a partir de encontrar las unidades significantes, enlistarlas y reagruparlas bajo el término de elementos.

Los elementos del dibujo están cada uno ocupando un espacio, sin aparente relación de unos con otros, salvo por la armonía o la totalidad de la imagen; más en el caso de Antonio y Clara que integran mayor cantidad de elementos que les son cotidianos con un menor grado de mediación escolar formal, ya que ellos no asistieron a una escuela oficial, sólo conocieron la escuela autónoma. Cada elemento representa un concepto y una idea que forma parte de un conjunto mayor, la idea de La escuela. Los elementos no se confunden uno con el otro. Solo hay un primer plano, no hay dimensión ni profundidad en la imagen. Un plano donde se ordenan signos, una forma de escritura ideográfica, sencilla. Los dibujos también representan un plano exterior: hay sol, o soles, hay nubes. Parece el retrato de un momento, la escena está estática, aunque en el dibujo de Clara los sujetos están en acción y fuera del aula.

\section{Conclusiones}

Los elementos del dibujo remiten a una idea o concepto estructurador que es $L a$ escuela, que sirvió de guía para la producción de dibujos y en este ejercicio se conciben como campos semánticos, espacios de significado, caminos de sentido o prácticas sociales. Son precisamente esas prácticas sociales las que busca la etnografía y gracias al trabajo de campo, se puede establecer un contexto histórico, propio y vivo, que da sentido último a la lectura de los datos, es decir, la historia local como un parámetro indispensable para interpretar los signos del discurso, para el estudio de las identidades en los dibujos de los niños y las niñas.

El análisis de los dibujos en diálogo son una herramienta que, anclados en el trabajo etnográfico, permiten identificar los elementos culturales de la mirada de la niñez, 
aprendidos de su entorno. En esta propuesta también quedan integrados, dentro de análisis semióticos la importancia del contexto cultural para la interpretación de los dibujos, no para profundizar en la subjetividad de los sujetos, sino en las formas en que se comparten los modos de mirar y representar la realidad en contextos culturales concretos.

\section{Referencias}

ALEJOS, José. La palabra en la vida: dialogismo en la narrativa mesoamericana. México: UNAM, 2012.

ARTIGAS, Irene. El aguijón de lo posible: reflexiones en torno a la ecfrasis y la fotografía. In: VILLEGAS, Irlanda; REYES, David; ROJAS Carlos (Org.). ¿Qué es la literatura comparada? Impresiones actuales. Xalapa: Biblioteca Digital de Humanidades: Universidad Veracruzana, 2014. p. 55-70.

BAJTíN, Mijaíl. Estética de la creación verbal. Ciudad de México: Siglo XXI, 1998.

BARONNET, Bruno. Autonomía y educación indígena: las escuelas zapatistas de la Selva Lacandona de Chiapas. México, DC: Quito: Abya-Yala, 2012.

BARONNET, Bruno; MORA, Mariana; STAHLER-SHOLK, Richard (Org.). Luchas "muy otras". Zapatismo y autonomía en las comunidades indígenas de Chiapa. Ciudad de México: UAM-X: CIESAS: UNACH, 2011.

BERTELY, María. La historial social de la escolarización en pueblos indígenas y tribales: múltiples maneras de vivir la escuela. In: BERTELY, María; PODESTÁ, Rossana; GASCHÉ, Jorge (Org.). Educando en la diversidad cultural. Quito: Abya-Yala: CIESAS: IIAP, 2008. p. 33-56.

COMISIÓN SEXTA. El pensamiento crítico frente a la hidra capitalista I. Chiapas: EZLN, 2015.

CORONA Sarah. Entre voces... Fragmentos de educación "entrecultural". Guadalajara: Universidad de Guadalajara, 2007.

CORONA Sarah; KALTMEIER, Olaf. En diálogo: metodologías horizontales en ciencias sociales y culturales. Barcelona: Gedisa, 2012.

CROS, Edmond. El sujeto cultural, sociocrítica y psicoanálisis. Buenos Aires: Corregidor, 1997.

DENZIN, Norman. Emancipatory discourses and the ethics and politics of interpretation. In: DENZIN, Norman; LINCOLN, Yvona; TUHIWAI, Linda (Orgs.). The sage Handbook of qualitative research. California: Sage, 2005. p. 933-958.

EZQUERRO, Milagros. Leerescribir. México; París: Rilma 2: Adehl, 2008a.

EZQUERRO, Milagros. Lecturas Rulfianas. Revista Libro Palabras Escritas, Asunción, n. 6, 2008b. Disponible en: http://palabras2008.blogspot.mx/search?q=ezquerro. Acceso en: 14 oct. 2015.

JIMÉNEZ NARANJO, Yolanda. Cultura comunitaria y escuela intercultural: más allá de un contenido escolar. México, DC: SEP-CGEIB, 2009. 
MEDINA MELGAREJ0, Patricia. Configuración de fronteras, interculturalidad y políticas de identidad. Tramas, Ciudad de México, n. 28, p. 171-194, 2007. Disponible en: http://tramas.xoc.uam.mx/tabla_contenido. php?id_fasciculo=276. Acceso en: 06 my 2011.

NúÑEZ, Kathia. Conocimiento, conciencia y práctica: aprendizaje en la educación autónoma zapatista. Argumentos, México, DC, n. 73, p. 81-92, 2013.

NÚÑEZ, Kathia. Construcción identitaria de niños y niñas en dos comunidades indígenas, desde sus discursos y prácticas de tres ámbitos de sentido: la comunidad, la casa y la escuela. 2018. 432 p. Tesis (Doctorado) - Instituto de Investigaciones en Educación, Universidad Veracruzana, Veracruz, 2018.

NÚÑEZ, Kathia. Socialización infantil en dos comunidades ch'oles: rupturas y continuidades: escuela oficial y escuela autónoma. 2005. 260 p. Tesis (Maestría - Antropología Social) - Centro de Investigaciones y Estudios Superiores en Antropología Social, Unidad Sureste, San Cristóbal de las Casas, 2005.

PÉREZ RUÍZ, Maya. La comunidad indígena contemporánea: límites, fronteras y relaciones interétnicas. In: LISBONA Migues. La comunidad a debate: reflexiones sobre el concepto de comunidad en el México contemporáneo. México, DC: El Colegio de Michoacán: Unicach, 2009. p. 87-100.

QUIJANO, Aníbal. Colonialidad del poder, eurocentrismo y América Latina. In: LANDER, Edgardo (Ed.). La colonialidad del saber: eurocentrismo y ciencias sociales: perspectivas Latinoamérica. Buenos Aires: Clacso, 2000. p. 201-246.

VAN DIJK, Teun.Texto y Contexto: semántica y pragmática del discurso. Madrid: Cátedra,1980.

Recibido en: 07.05.2020

Revisado en: 01.07.2020

Aprobado en: 04.08.2020

Kathia Núñez Patiño es doctora en Investigación Educativa por el Instituto de Investigaciones en Educación (IIE) de la Universidad Veracruzana y maestra en Antropología Social por el CIESAS-Sureste. Integrante del Cuerpo Académico "Infancia y juventud en contextos de diversidad". Integrante del Sistema Nacional de Investigadores (N.1). Integrante fundadora de la Red Latinoamericana de Investigación y Reflexión con Niños, Niñas y Jóvenes (REIR) 